\title{
Profil Status Identitas Religius pada Remaja Akhir
}

\section{Galuh Prawitasari}

KORESPONDEN PENULIS:

Galuh Prawitasari

Universitas Negeri Yogyakarta

Jalan Colombo Nomor 1, Kota

Yogyakarta, Daerah Istimewa

Yogyakarta, Indonesia

Email: prawitasari.galuh@gmail.com

Halaman

$104-110$

\begin{abstract}
This study aimed to find out the profile of religious identity on late adolescents. This was a quantitative study with descriptive survey design. The subject of this study was 134 students of Guidance and Counseling Department of Yogyakarta State University who were taken by simple random sampling technique. The data were collected through Religious Identity scale. The data were analyzed by using descriptive statistics. The result of this study showed that 100 subjects were in the achievement status (75\%), 27 subjects were in the searching moratorium status (20\%), and seven subjects were in the foreclosure status (5\%). The result of this study took a role as the basis for formulating a guidance and counseling service to develop the religious identity on late adolescents.

Keywords: religious identity, late adolescents, descriptive survey
\end{abstract}

\begin{abstract}
ABSTRAK
Studi ini bertujuan untuk mengetahui profil status identitas religius remaja akhir. Studi menggunakan pendekatan kuantitatif dengan jenis survey diskriptif. Jumlah subjek dalam studi ini sebanyak 134mahasiswa Jurusan Bimbingan dan Konseling Universitas Negeri Yogyakarta yang ditentukan melalui teknik simple random sampling. Instrumen pengumpulan data menggunakan skala status identitas religius, sedangkan teknik analisis data menggunakan statistik deskriptif. Hasil studi menunjukkan bahwa 100 subjek berada dalam status achievement (75\%), 27 subjek berada dalam status searching moratorium (20\%), dan 7 subjek berada dalam status foreclosure (5\%). Hasil studi berperan sebagai dasar dalam merumuskan layanan bimbingan dan konseling untuk pengembangan identitas religius pada remaja akhir.

Kata kunci: identitas religius, remaja akhir, survey deskriptif
\end{abstract}




\section{PENDAHULUAN}

Masa remaja sebagai masa transisi dari masa kanakkanak menuju masa dewasa sering kali disalahtafsirkan dengan melakukan eksplorasi diri yang tidak terarah dan tidak bertanggung jawab. Bagi remaja yang menempuh pendidikan Perguruan Tinggi, tantangan yang harus dihadapi semakin kompleks. Pada usia 17 hingga 19 tahun, remaja di Indonesia umumnya mengalami suatu babak transisi baru dalam hidupnya, yakni berpindah dari jenjang pendidikan SMA menuju jenjang pendidikan Perguruan Tinggi. Perpindahan ini melahirkan beberapa dampak bagi remaja, baik dampak positif maupun dampak negatif. Pada jenjang Perguruan Tinggi misalnya, mahasiswa cenderung dituntut untuk lebih mandiri. Tuntutan akan kemandirian tersebut juga berkaitan dengan aspek akademik dimana mahasiswa cenderung dituntut untuk lebih proaktif dalam menambah khasanah ilmu pengetahuan dan lebih mandiri dalam mengembangkan kemampuan akademiknya. Berbagai "tuntutan" baik secara sosial maupun secara akademik yang melingkupi dunia baru remaja di perguruan tinggi dapat menimbulkan berbagai permasalahan remaja.

Mahasiswa baru yang tergolong pada fase remaja akhir rentan untuk terjerumus ke dalam fenomena kebingungan identitas yang dapat termanifestasi dalam perilaku-perilaku negatif. Meski demikian, ada pula sebagian mahasiswa lainnya yang mampu lepas dari jebakan kebingungan identitas tersebut dan melahirkan perilaku-perilaku yang dinilai positif oleh lingkungan.

Riset Kroger selama beberapa tahun (2007) terhadap mahasiswa pada fase remaja akhir yang diwawancarai menunjukkan adanya ketakutan terhadap berbagai tanggung jawab yang secara nyata harus dihadapi saat dewasa, keragu-raguan terhadap kemampuan dalam mengatasinya, dan harapan untuk menemukan kehidupan yang lebih bermakna sekaligus diiringi oleh rasa takut akan kegagalan. Selain itu, riset terkini dari Howard \& Galambos (2011) menunjukkan bahwa peralihan dari masa remaja akhir ke masa dewasa terjadi pada berbagai aspek seperti, kebingungan dalam pekerjaan, pendidikan, perguruan tinggi, kesibukan pekerjaan, pengangguran, perubahan tempat tinggal, pasangan romantis, serta perbedaan budaya dari status SMA menuju mahasiswa.

Merujuk pada terminologi psikologi, kondisi kebimbangan yang kerap dialami oleh remaja disebut sebagai kebingungan identitas (Erikson, 1968). Menurut Erikson identitas versus kebingungan identitas merupakan tahap perkembangan yang akan berlangsung selama masa remaja. Pada tahap ini remaja akan dihadapkan pada banyak peran dan menemui beragam persoalan tentang siapa mereka, apa yang penting untuk mereka, dan apa yang hendak dituju dalam hidup. Remaja yang mampu menghadapi peran dan identitas yang saling bertentangan akan memiliki suatu kesadaran yang baru dan dapat diterima tentang dirinya, sedangkan remaja yang gagal melalui krisis identitas akan mengalami kebingungan identitas (Santrock, 2014)

Teori identitas Erikson dielaborasi lebih dalam oleh Marcia (1993) dengan melakukan kategorisasi status identitas individu menjadi empat, yaitu diffusion, foreclosure, moratorium, dan achievement. Keempat status identitas tersebut merepresentasikan cara remaja dalam mengatasi krisis identitas dan penggolongannya didasarkan pada besar kecilnya aktivitas eksplorasi dan komitmen remaja. Crocetti, et al. (2008) mengembangkan teori empat status identitas Marcia dengan menambahkan status kelima, yakni searching moratorium. Model lima status identitas tersebut didasarkan pada aktivitas individu dalam tiga aspek: commitment, in-depth exploration, dan reconsideration of commitment.

Status identitas remaja pada suatu domain dapat berbeda dengan domain lainnya (Goossens, 2001; Fadjukoff, Pulkkinen, \& Kokko, 2005). Seorang remaja dapat memiliki status identitas yang achieved pada suatu domain, namun diffused pada domain lainnya. Pada umumnya para ahli identitas menggolongkan domain-domain tersebut menjadi dua klasifikasi besar, yakni ideological dan interpersonal (Bartoszuk \& Pittman, 2010).Domain ideological meliputi domain karir, politik, religius, dan nilai moral, sedangkan domain interpersonal meliputi domain relasi dengan keluarga, sahabat, dan teman dekat/pacar.

Marcia (2001) menyatakan bahwa salah satu strategi dalam memilih domain adalah dengan menilai domain yang dianggap penting pada masa tersebut. Domain religius merupakan salah satu domain yang vital untuk dikaji pada masa remaja (Park, et al. dalam Santrock, 2014). Pemahaman yang menyeluruh mengenai pengalaman religius 
remaja merupakan hal yang penting mengingat pengembangan identitas yang substansial terjadi selama periode ini (Fowler \& Dell, 2006). Erikson (1968) mencirikan masa remaja sebagai suatu periode krisis dimana remajaberupaya menentukan kedudukannya didunia. Sebuah komponen kunci selama proses ini adalah dengan mengadopsi suatu sistem kepercayaan tertentu (belief) yang dapat menginformasikan kepada remaja pandangan tentang dunia dan agama merupakan salah satu sumber kepercayaan semacam itu (Davis \& Kiang, 2016).

Beberapa riset telah membuktikan adanya hubungan positif antara identitas religius dengan beberapa variabel psikologis lain, seperti psychological well-being (AbuRayya, Abu-Rayya, \& Khalil, 2009; Francis \& Katz, 2002; Francis \& Robbins, 2000; Hackney \& Sanders, 2003; Helm, Hays, Flint, Koenig, \& Blazer, 2000; Koenig \& Larson, 2001; Leondari \& Gialamas, 2009; Lewis, Maltby, \& Day, 2005), self-esteem, positive affect, dan kebermaknaan hidup (Davis \& Kiang, 2016; Chan, Tsai, \& Fuligni, 2014). Studi lain menunjukkan bahwa individu yang mempunyai religiusitas tinggi akan memengaruhi tingkat kepuasan hidup individu tersebut (Diponegoro \& Ru'iya, 2013). Hasil-hasil penelitian tersebut semakin mengukuhkan pentingnya kajian tentang status identitas religius, terutama pada remaja akhir.

Studi bertujuan untuk mengetahui profil identitas religius pada remaja akhir. Remaja pada masa ini sedang mengalami proses restrukturisasi hubungan sosial dan menentukan pilihan-pilihan penting untuk kehidupan mereka di masa depan. Hasil studi dapat digunakan untuk mengembangkanprogram/intervensi dalam layanan bimbingan dan konseling di Perguruan Tinggi bagi remaja akhir agar identitas religiusnya mampu berkembang menuju status achievement.

\section{METODE PENELITIAN}

Studi menggunakan pendekatan kuantitatif dengan jenis survey diskriptif. Jumlah subjek dalam studi ini sebanyak 134mahasiswa Jurusan Bimbingan dan Konseling Universitas Negeri Yogyakarta yang ditentukan melalui teknik simple random sampling. Instrumen pengumpulan data menggunakan skala status identitas religius, sedangkan teknik analisis data menggunakan analisis statistik deskriptif.

\section{HASIL DAN PEMBAHASAN}

Analisis statistik deskriptif terhadap skala status identitas religius menunjukkan bahwa sebagian besar subjek penelitian berada pada status status achievement(75\%). Secara lebih rinci, hasil analisis statistik deskriptif divisualisasikan pada Gambar 1.

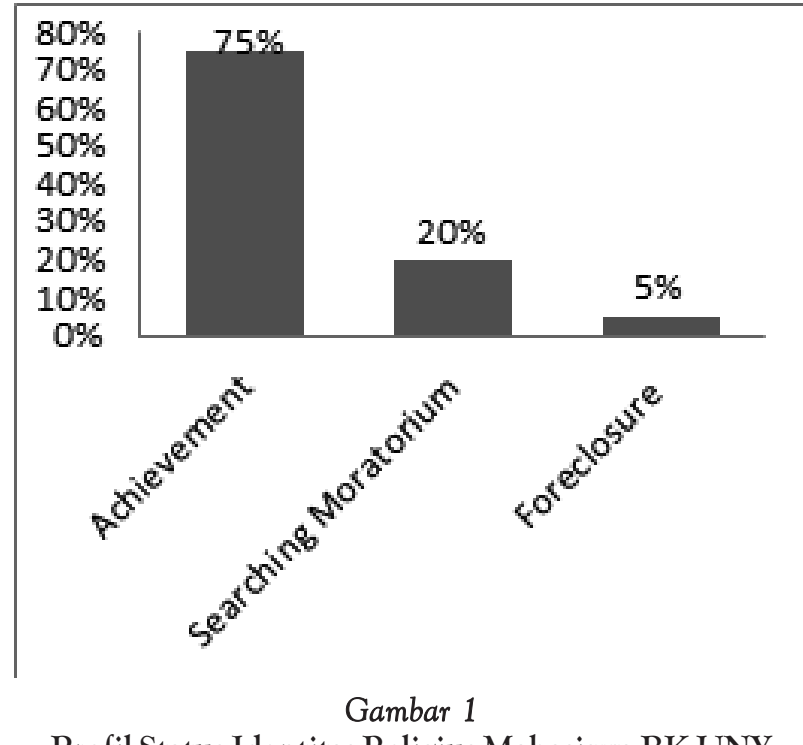

Profil Status Identitas Religius Mahasiswa BK UNY

Status identitas religius adalah suatu kerangka konsep yang didefinisikan sebagai eksplorasi dan komitmen terhadap wilayah tertentu dari religi/agama (Griffith \& Griggs, 2001). Proses pembentukan status identitas religius pada remaja meliputi tiga aspek, yaitu komitmen, eksplorasi mendalam (in-depth exploration), dan pertimbangan kembali komitmen (reconsideration of commitment). Komitmen merupakan upaya remaja dalam menjalani pilihan yang sifatnya cenderung menetap dalam domain religius serta rasa percaya diri yang lahir dari proses menjalani pilihan tersebut. Eksplorasi mendalam (in-depth exploration) merepresentasikan sejauh mana remaja mampu berpikir aktif tentang komitmen yang telah dipilih berkaitan dengan domain religius, merefleksikan pilihan-pilihan yang ada, mencari informasi-informasi tambahan tentang komitmennya, dan berbicara dengan orang lain tentang komitmen tersebut. Pertimbangan kembali dari komitmen (reconsideration of commitment) merujuk pada upaya membandingkan komitmen yang telah diambil saat ini dengan 
alternatif-alternatif pilihan lain yang muncul yang berkaitan dengan domain religius karena komitmen sebelumnya dianggap sudah tidak memuaskan. Berdasarkan tinggi atau rendahnya aktivitas remaja pada ketiga aspek tersebut, dapat ditentukan lima kemungkinan status identitas, yaitu achievement, searching moratorium, moratorium, foreclosed, dan diffused (Crocetti, Rubini, \& Meeus, 2008).

Menurut Kroger (2007) individu yang tergolong sebagai remaja akhir berada dalam rentang usia 17-24 tahun. Pada masa ini pengembangan identitas menjadi salah satu fokus utama yang dialami remaja dan juga dewasa awal (Kroger, Martinussen, \& Marcia dalam Santrock, 2011). Sebagai upaya dari pencarian identitas, remaja maupun dewasa awal mulai bergumul dengan pertanyaan-pertanyaan yang lebih filosofis, seperti "Mengapa saya ada di dunia ini?" "Apakah Tuhan benar-benar ada?" "Apakah agama yang saya anut saat ini merupakan agama warisan saja?" Ditinjau dari perkembangan kognitifnya, individu dalam masa remaja berpikir lebih abstrak, lebih idealis, dan lebih logis dibanding individu dalam masa kanak-kanak. Cara berpikir abstrak yang lebih meningkat ini membuat remaja mulai memikirkan konsep-konsep tentang religiusitas dan spiritualitas. Selain itu kemampuan remaja untuk berpikir secara lebih logis membuat remaja mampu mengembangkan hipotesis dan memilih secara sistematis jawaban-jawaban atas berbagai pertanyaan spiritual mereka (Good \& Willoughby, dalam Santrock, 2011). Oleh karena itu, perkembangan identitas pada masa remaja akhir yang positif akan menjadi dasar bagi perkembangan dewasa yang positif pula.

Perkembangan identitas yang positif direpresentasikan oleh status identitas achievement. Menurut Griffith \& Griggs (2001) remaja dengan status identitas religius achievement akan mulai menginternalisasi keyakinan dan nilainilai religius yang dimilikinya setelah remaja melalui masa pencarian dan masa mempertanyakan. Proses internalisasi ini biasanya diiringi dengan perubahan pengalaman (Gorsuchdalam Griffith \& Griggs, 2001). Religiusitas saat ini bagi remaja dengan status achievement merupakan motivasi intrinsik dan akan terus diikuti sampai akhir (Allport dalam Griffith \& Griggs, 2001). Sanders (dalam Griffith \& Griggs, 2001) menyatakan bahwa individu yang memiliki identitas religius pada tahap achievement memiliki keyakinan yang matang dan terintegrasi dan didefinisikan sebagai pelayanan akan kemanusiaan dan pelayanan diri akan realitas transendensi.

Status achievement merepresentasikan status identitas paling sehat bagi remaja. Status identitas achievement dicirikan dengan tingkat komitmen dan in-depth exploration yang tinggi, namun rendah dalam reconsideration of commitment. Beberapa riset membuktikan bahwa remaja yang memiliki identitas yang matang (status achievement) menunjukkan skor yang tinggi dalam berbagai aspek fungsi psikologis (meliputi self-esteem, internal locus of control, psychological well-being, kepuasaan terhadap hidup, realisasi dan penyesuaian diri), memiliki profil kepribadian yang positif, serta memiliki tingkat kesadaran dan kestabilan emosi yang tinggi (Schwartz, et al., 2011; Meeus, 2011).

Status identitas searching moratorium memiliki kemiripan dengan status achievement dalam aspek komitmen dan in-depth exploration yang tinggi, namun berbeda dalam aspek reconsideration of commitment yang rendah. Adapun status identitas foreclosure dicirikan dengan tingkat komitmen yang tinggi, namun rendah dalam aspek in-depth exploration dan reconsideration of commitment.

Berkaitan dengan masalah psikososial, Crocetti et al. (2008) menemukan adanya perbedaan yang signifikan di antara remaja-remaja dalam tiga status identitas tersebut. Remaja dalam status achievement dan foreclosuredicirikan oleh rendahnya tingkat masalah psikososial,sedangkan remaja dalam status searching moratorium melaporkan lebih banyak masalah psikososial yang bersifat internalized maupun externalized behavior. Secara keseluruhan, temuan riset ini menyoroti bahwa status yang dicirikan oleh tingkat komitmen yang moderat hingga tinggi yang berkaitan dengan rendahnya tingkat reconsideration of commitment (misalnya pada status achievement dan foreclosure) menunjukkan kondisi stabilitas identitas, sedangkan status dengan komitmen yang rendah dan atau reconsideration of commitmentyang tinggi (seperti statussearching moratorium) menunjukkan kondisi ketidakstabilan identitas yang diindikasikan dari tingginya gejala-gejala depresi dan kecemasan.

Berkaitan dengan hasil studi tentang status identitas religius, maka diperlukan pengembangan status identitas religius pada remaja akhir yang sedang menempuh pendidikan di Perguruan Tinggi. Pengembangan status 
identitas religius tersebut, dapat dilakukan oleh unit Bimbingan dan Konseling di Perguruan Tinggi. Layanan BK yang berfungsi preventif atau developmental sebaiknya diberikan kepadaremaja yang berada dalam status identitas achievement, sedangkan layanan BK yang berfungsi kuratif atau perbaikan sebaiknya diberikan kepada remajayang berada dalam status identitas searching moratorium dan foreclosure.

Layanan BK yang berfungsi preventif atau development layak diberikan kepada remaja yang berada pada status identitas religius achievement. Remaja dengan status identitas religius achievementmemiliki permasalahan psikososial yang lebih rendah dibandingkan dengan remaja dalam status identitas lainnya. Meski demikian keberadaan remaja dalam status achievement saat ini dapat berubah karena pembentukan identitas selama masa remaja dan dewasa awal bersifat tidak permanen untuk periode kehidupan selanjutnya (McAdams \& Cox, 2010).

Banyak individu yang telah mengembangkan identitas yang positif mengikuti siklus "MAMA" (moratoriumachievement-moratorium-achievement) (Marcia, 1994) dan siklus ini dapat berulang sepanjang hidup individu (Francis, Fraser, \& Marcia dalam Santrock, 2014:149). Marcia (2002) juga menyatakan bahwa identitas pertama yang mampu dibentuk oleh individu bukanlah menjadi identitas yang final bagi dirinya. Oleh karena itu, dibutuhkan layanan BK yang bertujuan untuk mempersiapkan remaja dalam status achievement saat ini guna menghadapi periode siklus MAMA.

Remaja yang menghadapi siklus MAMA akan memasuki status moratorium sebelum akhirnya mencapai status achievement kembali. Pada status moratorium inilah remaja akan mengalami krisis identitas yang didefinisikan sebagai suatu masa perkembangan identitas di mana remaja memilahmilah beberapa alternatif yang berarti dan yang tersedia. Akibatnya, remaja dalam status moratorium akan cenderung mengalami ketidakstabilan identitas. Berkaitan dengan hal tersebut, layanan BK yang diperlukan adalah layanan yang berfungsi preventif, yakni layanan yang bertujuan sebagai upaya pencegahan remaja dalam status achievement agar tidak mengalami kondisi ketidakstabilan identitas yang berkepanjangan saat menghadapi siklus MAMA kelak. Salah satu layanan BK yang dipandang tepat sebagai upaya pencegahanyaitu layanan bimbingan kelompok.

Remaja dalam status searching moratorium hanya berbeda dalam aspek reconsideration of commitment dibanding remaja dalam status achievement. Remaja dalam status searching moratorium memiliki tingkat reconsideration of commitment yang tinggi. Sebaliknya, remaja dalam status achievement memiliki tingkat reconsideration of commitment yang rendah. Tingkat reconsideration of commitment yang tinggi menunjukkan adanya penurunan kepuasan terhadap komitmen yang saat ini dipilih oleh remaja. Di sisi lain, remaja dalam status searching moratorium tetap melakukan in-depth exploration dengan tingkat yang tinggi. Kondisi ini membuat remaja berada dalam kondisi ketidakstabilan identitas. Oleh karena itu, layanan BK yang direkomendasikan bagi remaja dalam status identitas searching moratorium adalah layanan BK yang berfungsi kuratif berupa konseling individu maupun kelompok dengan pendekatan person-centeredkarena pada dasarnya konseling memiliki peran penting dalam mengubah pandangan hidup dan perilaku seseorang (Diponegoro, 2012).

Asumsi masalah menurut pendekatan konseling person-centered adalah bahwa masalah timbul sebagai akibat dari adanya discrepancy (kesenjangan) antara ideal-self dan real-self. Tugas konselormembantu konseli untuk memperkecil atau bahkan menghilangkan kesenjangan tersebut. Berkaitan dengan status identitas religius, konselor membantu konseli untuk mengidentifikasi gambaran ideal-self maupun real-self dari religiusitas konseli saat ini. Konselor berupaya untuk menciptakan atmosfer konseling yang penuh dengan unconditional positive regard serta memberikan accurate emphatetic understanding atas kondisi disekuilibrium yang dialami konseli. Kedua strategi tersebut dilakukan agar konseli bersedia mengungkap ketidakpuasan-ketidakpuasan yang dirasakan konseli terhadap komitmen religiusitasnya saat ini. Selain itu, konselor perlu untuk mengungkapkan genuine untuk memberi batasanbatasan normatif atas ketidakpuasan yang dirasakan oleh konseli.

Status identitas foreclosure ditandai dengan tingginya tingkat komitmen dan rendahnya tingkat in-depth exploration. Akibatnya, remaja yang foreclosure cenderung konformis terhadap nilai-nilai yang dianut oleh lingkungan 
sekitarnya. Remaja yang foreclosure enggan untuk mengeksplorasi lebih jauh terkait pilihan religius yang telah diambil sehingga cenderung mengadopsi nilai-nilai religius secara mentah-mentah tanpa penghayatan yang mendalam. Bagi remaja yang foreclosure upaya untuk melakukan eksplorasi akan memunculkan rasa bersalah dan kecemasan dalam dirinya (Marcia, 1994). Oleh karena itu, layanan BK yang dibutuhkan untuk remaja dalam status identitas foreclosure adalah layanan konseling yang bertujuan untuk meningkatkan kepercayaan diri konseli. Hal tersebut dilakukan agar konseli mampu mengungkapkan kebutuhankebutuhannya dalam mengeksplorasi lebih jauh terkait pilihan religius yang telah diambil tanpa disertai dengan perasaan bersalah atau cemas.

Peningkatan percaya diri dapat dilakukan dengan menggunakan berbagai teknik, salah satunyaassertive training. Menurut Bishop (1999) asertivitas akan mengembangkan kepercayaan diri dan kemampuan diri dalam menilai, berpendapat, dan menghormati orang lain. Asumsi dasar dari teknik assertive training adalah bahwa setiap orang mempunyai hak untuk mengungkapkan perasaannya, pendapat, keyakinannya, serta sikap untuk melakukan suatu hal tanpa ragu tetapi tidak menyakiti perasaan orang lain. Assertive training merupakan latihan keterampilansosial yang diberikanpada individu yang diganggu kecemasan, tidak mampu mempertahankan hak-haknya, terlalu lemah, membiarkan orang lain merongrong dirinya, tidak mampu mengekspresikan amarahnya dengan benar dan cepat tersinggung (Corey, 2009). Oleh sebab itu, assertive training dipandang tepat jika digunakan untuk meningkatkan kepercayaan diri bagi remaja yang berada dalam status identitas religiusforeclosure.

\section{SIMPULAN}

Hasil studi menunjukkan bahwa75\% remaja akhir berada dalam status achievement, $20 \%$ berada dalam status searching moratorium, dan $5 \%$ berada dalam status foreclosure. Hasil studi dapat digunakan untuk mengembangkan program/intervensi bagi remaja akhir yang menempuh pendidikan di Perguruan Tinggi agar dapat mengembangkan status identitas religius ke arah status achievement. Rekomendasilayanan BK untuk remaja dengan status achievement yaitu dengan bimbingan kelompok, status searching moratoriumdengan konseling individual atau kelompokpendekatan person-centered, dan status foreclosuredenganlayanan konseling individual atau kelompokteknik assertive training.

\section{REFERENSI}

Abu-Rayya, M. H., \& Abu-Rayya, H. M. (2009). Ethnic Identification, Religious Identity, and Psychological Well-being Among MUSLIM and Christian Palestinians in Israel. Mental Health, Religion, $\mathfrak{G}$ Cul ture Journal, 12, 147-155.

Bartoszuk, K., Pittman, J. F. (2010). Profiles of Identity Exploration and Commitement Across Domain. Journal of Child and Family Study, 19, 444450.

Bishop, S. (1999). Assertiveness Skills Training. New Delhi: Viva Books Pivated Limited.

Chan, M., Tsai, K. M., \& Fuligni, A. J. (2014). Changes in Religiosity Across the Transition to Young Adulthood. Journal of Youth and Adolescence, 44(8), 15551566.

Corey, G. (2009). Teori dan Praktek Konseling dan Psikoterapi. Bandung: PT Refika Aditama.

Crocetti, E., Rubini, M., Luyckx, K., \& Meeus, W. (2008). Identity Formation in Early and Middle Adolescents From Various Ethnic Groups: From Three Dimensions to Five Statuses. Journal of Youth and Adolescence, 37, 983-996.

Davis, R. F., \& Kiang, L. (2016). Religious Identity, Religious Participation, and Psychological WellBeing in Asian American Adolescents. Journal of Youth and Adolescence, 45, 532-546.

Diponegoro, Ahmad Muhammad. (2012). Konseling dalam Islam. PSIKOPEDAGOGIA Jurnal Bimbingan dan Konseling, 1 (2), 193-206.

Diponegoro, Ahmad Muhammad. \& Ru'iya, Sutipyo. (2013). Peran Religiusitas Islami dan Kesejahteraan Subyektif terhadap Pemaafan Remaja Siswa Madrasah Aliyah Negeri III Yogyakarta. Psikopedagogia Jurnal Bimbingan dan Konseling,2(1).

Erikson, E. H. (1968). Identity: Youth and crisis. New York: Norton.

Fadjukoff, P., Pulkkinen, L., \& Kokko, K. (2005). Identity Processes in Adulthood: Diverging Domains. Identity: An International Journal of Theory and Research, 5, 1-20. 
Fowler, J. W., \& Dell, M. L. (2006). The Handbook of Spiritual Development in Childhood and Adolescence. California: Sage Publication, Inc.

Francis, L. J., \& Katz, Y. J. (2002). Religiosity and Happiness: As Study Among Israeli Female Undergraduates. Research in the Social Scientific Study of Religion Journal, 13, 75-86.

Francis, L. J., \& Robbins, M. (2000). Religion and Happiness: A Study in Empirical Theology. Transpersonal Psychology Review Journal, 4, 17-22.

French, S., \& Joseph, S. (1999). Religiosity and its Association with Happiness, Purpose in Life, and Self-actualization. Mental Health, Religion, $\mathcal{E}$ Culture Journal, 2, 117-120.

Goossens, L. (2001). Global Versus Domain-Specific Statuses in Identity Research: A Comparison of Two Self-report Measures. Journal of Adolescence, 24, 681-699.

Griffith, B. A., \& Griggs, J. C. (2001). Religious Identity Status as a Model to Understand, Assess, and Interact with Client Spirituality. Counseling and Values Journal, 46 (1),14.

Hackney, C., \& Sanders, G. (2003). Religiosity and Mental Health: A Meta-analysis of Recent Studies. Journal for the Scientific Study of Religion, 42, 43-55.

Helm, H., Hays, J. C., Flint, E., Koenig, H. G., \& Blazer, D. G. (2000). Effects of Private Religious Activity on Mortality of Elderly Disabled and Nondisabled Adults. Journal of Gerontology, 55, 400-405.

Howard, A. L., \& Galambos, N. L. (2011). Transitions to Adulthood-Encyclopedia of Adolescence, 1.

Koenig, H. G., \& Larson, D. B. (2001). Religion and Mental Health: Evidence of Association. International Review of Psychiatry Journal, 13, 67-78.

Kroger, J. (2007). Identity Development ( $\left.2^{\text {nd }} e d\right)$. California: Sage Publication, Inc.

Leondari, A., \& Gialamas, V. (2009). Religiosity and Psychological Well-being. International Journal of Psychology, 44 (4), 241-8.

Lewis, C. A., Maltby, J., \& Day, L. (2005). Religious Orientation, Religious Coping, and Happiness among UK Adults. Personality and Individual Differences Journal, 38, 1193-1202.

Marcia, J. E. (1993). Handbook for Psychosocial Research. New York: Springer Verlag.

Marcia, J. E. (1994). Identity and Development. Califor- nia: Sage Publication, Inc.

Marcia, J. E. (2001). A Commentary on Seth Schwartz's Review of Identity Theory and Research. Identity: An International Journal of Theory and Research, 1, 59-65.

Marcia, J. E. (2002). Identity and Psychosocial Development in Adulthood. Identity: An International Journal of Theory and Research, 27-2.

Matteson, D. R. (1993). A Handbook for Psychosocial Research. New York: Springer Verlag.

McAdams, D. P., \& Cox, K. S. (2010). Handbook of Life-span Development (Vol. 2). New York: Wiley.

Meeus, W. (2011). The Study of Adolescent Identity Formation 2000-2010: A Review of Longitudinal Research. Journal of Research in Adolescence, 21, 7584.

Santrock, J. W. (2014). Adolescence (15 ${ }^{\text {th }}$ ed). New York: McGraw-Hill Companies, Inc.

Schwartz, S. J., Beyers, W., Luyckx, K., Soenens, B., Zamboanga, B. L., Forthun, L. F., Hardy, S. A., Vazsonyi, A. T., Ham, L. S., Kim, S. Y., Whitbourne, S. K., \& Waterman, A. S. (2011). Examining the Light and Dark Sides of Emerging Adults' Identity: A Study of Identity Status Differences in Positive and Negative Psychosocial Functioning. Journal of Youth and Adolescence, 40, 839859. 